Portland State University

PDXScholar

$1-2009$

\title{
Parental Alcoholism and Family Functioning: Effects on Differentiation Levels of Young Adults
}

Patrick Johnson

Portland State University

Rachel Stone

Portland State University

Follow this and additional works at: https://pdxscholar.library.pdx.edu/coun_fac

Part of the Educational Psychology Commons, and the Student Counseling and Personnel Services Commons

Let us know how access to this document benefits you.

\section{Citation Details}

Johnson, Patrick and Stone, Rachel, "Parental Alcoholism and Family Functioning: Effects on Differentiation Levels of Young Adults" (2009). Counselor Education Faculty Publications and Presentations. 60.

https://pdxscholar.library.pdx.edu/coun_fac/60

This Post-Print is brought to you for free and open access. It has been accepted for inclusion in Counselor Education Faculty Publications and Presentations by an authorized administrator of PDXScholar. Please contact us if we can make this document more accessible: pdxscholar@pdx.edu. 
Running head: PARENTAL ALCOHOLISM

Parental Alcoholism and Family Functioning:

Effects on Differentiation Levels of Young Adults

\author{
Patrick Johnson \\ Rachel Stone \\ Portland State University
}

Patrick Johnson, Ph.D., is associate professor in the Counselor Education Program at Portland State University. Rachel Stone is a recent graduate of the Counselor Education Program at Portland State University. Please address all correspondence to Dr. Patrick Johnson at: Counselor Education Program, Portland State University, PO Box 751, Portland, OR, 97207-0751. email: johnsonp@pdx.edu. 503-725-9764. 
PARENTAL ALCOHOLISM 2

\begin{abstract}
This study investigated the impact of parental alcoholism and various indices of family functioning on differentiation levels of young adults. Eight hundred and thirteen colleges students completed the Differentiation of Self Inventory (DSI; Skowron \& Friedlander, 1998), the Self-Report Family Inventory Version II (SFI; Beavers \& Hampson, 1990), and questions related to experiences in their families of origin. Analyses indicated that parental alcoholism and levels of functioning as well as certain experiences within alcoholic families are significantly predictive of differentiation levels of adult children. Clinical implications of the findings are discussed.
\end{abstract}

Key words: Parental alcoholism, Adult children of alcoholics, Differentiation, Bowen theory 


\section{Parental Alcoholism and Family Functioning:}

Effects on Differentiation Levels of Young Adults

Results of national epidemiologic surveys on alcohol use and related conditions indicate that there is a significant increase in the number of American adults with alcohol dependence or alcohol abuse over the past 10 years (Grant et al, 2004). An estimated 3.8 million more adults have a drinking related problem in the 2001-2002 national survey as compared to the 1991-1992 survey, a jump from 13.8 million to 17.6 million in ten years. The number of children that have been exposed to alcohol abuse or dependence in the home is an estimated at $28.6 \%$, roughly 1 in 4 children (Grant, 2001). Furthermore, $43 \%$ of children in the United States have lived with at least one individual with a past or present alcohol abuse or dependence problem.

Children and families contend with a variety of detrimental effects from parental alcoholism (Campbell, Masters, \& Johnson, 1998; Deming, Chase, \& Karesh, 1996; Hall \& Webster, 2002; Harter, 2000; Johnson, 2001; Jones, \& Kinnick, 1995). For example, communication in alcoholic families is often more negative than in nonalcoholic families (Sheridan \& Green, 1993). Alcoholic families also exhibit higher levels of openly expressed anger and lower levels of warmth towards other family members (Deming, et al, 1996; Garbarino \& Strange, 1993; Johnson, 2001; Senchak, Leonard, Greene, \& Carroll, 1995). Specifically, alcoholic families experience higher levels of family conflict including blaming, fighting, and arguing. In addition, parental alcoholism is associated with children assuming the caretaker role, role confusion, and generational boundary distortions (Chase, Deming, \& Wells, 1998; Devine \& Braithwaite, 1993; Goglia, Jurovic, Burt, \& Burge-Callaway, 1992; Sheridan \& Green, 1993). 
Adult Children of Alcoholics (ACOAs) tend to perceive their families of origin as less healthy than their non-ACOA counterparts (Deming, et al, 1996; Kerr \& Hill, 1992a). Research supports their perception, finding lower overall family health and competence and an association between parental alcoholism and increased levels of certain types of family dysfunction (Fischer et al., 2000; Garbarino \& Strange, 1993; Johnson, 2001, 2002; Senchak et al., 1995). Alcoholic families are more likely to experience divorce and multigenerational transmission of alcoholism (Hall et al., 1994; Johnson, 2001; Kerr \& Hill, 1992b). In addition, ACOAs are more likely to have experienced traumatic childhood events than non-ACOAs (Anda et al., 2002; Hall \& Webster, 2002; Johnson, 2001). Specifically children in alcoholic families are at a greater risk for physical, sexual, and emotional child abuse and neglect (Harter, 2000; Harter \& Vanecek, 2000; Kerr \& Hill, 1992a; Melchert, 2000) and witnessing spousal abuse and violence (Johnson, 2001; Hall et al., 1994).

Specific experiences may moderate or exacerbate the impact of familial alcoholism on children and family functioning (Anda et al., 2002; Harter \& Vanecek, 2000; Johnson, 2002). Parental divorce (Johnson, 2002), parental availability (Hardwick, Hansen, \& Baimsfather, 1995; Johnson, 2002; Melchert, 2000) and predictability of parental behavior (Hawkins, 1997; Johnson, 2002) in alcoholic families, for example, have been shown to increase the level of family functioning. When ACOAs live with an alcoholic parent for an extended period of time, witness spousal violence, or are abused or neglected, family functioning falters (Johnson, 2002).

Literature suggest that the level of family dysfunction in alcoholic families contributes to adult outcomes (Ellis, Zucker, \& Fitzgerald, 1997; Harter, 2000; Harter \& Taylor, 2000; Johnson, 2002). For example, ACOAs with a history of emotional abuse had more difficultly with social adjustment particularly in the school and work arenas (Harter \& Taylor, 2000). 
These individuals have difficulty with social and task focused strategies. Many ACOAs have difficulty with psychological and psychosocial adjustment (Hall \& Webster, 2002; Senchak et al., 1995), including increased risk for mood, anxiety, and alcohol and drug use disorders and more negative consequences associated with alcohol and drug use (Cuijpers, Langendoen, \& Bijl, 1999; Chassin, Pitts, DeLucia, \& Todd, 1999; Sher, Walitzer, Wood, \& Brent, 1991; Sher, 1997). ACOAs experience higher levels of state and trait anxiety than non-ACOAs, and ACOA status is a predictor|stress (Hall \& Webster, 2002; Maynard, 1997). ACOAs also have difficulty initiating effective coping styles when faced with stressful life events (Hall \& Webster, 2002; Hart \& McAleer, 1997).

Although a more comprehensive understanding of the effect of familial alcoholism is emerging, less is known about the longer-term developmental effects of parental alcoholism on adults. Questions remain regarding the effects of parental alcoholism on developmental tasks such as the differentiation process and intimacy in significant relationships with partners and children. Also, are there experiences within alcoholic families that moderate or exacerbate the effects of parental alcoholism on developmental tasks of young adults?

Results from Maynard (1997) suggest that ACOAs have lower levels of differentiation of self. ACOAs report lower levels of satisfaction with life and interpersonal relationships and more negative attitudes towards life situations than non-ACOAs (Beesley \& Stoltenberg, 2002; Hall et al., 1994; Kerr \& Hill, 1992b, Larson \& Thayne, 1998). ACOAs are more likely to marry another ACOA and experience lower levels of satisfaction with their marriage and with their own children and higher rates of divorce (Kerr \& Hill, 1992b). ACOAs also tend to experience a stronger need to control their environment (Beesley \& Stoltenberg, 2002; Hall et al., 1994; Shapiro, Weatherford, Kaufman, \& Broenen, 1994). 
PARENTAL ALCOHOLISM 6

The purpose of the present study was to assess the effects of parental alcoholism on the developmental task of differentiating from one's family of origin. Building on Maynard's (1997) findings, this study examined the impact of parental alcoholism on the differentiation level of young adults. The study also assessed the effects of specific dimensions of family functioning within alcoholic families, including indices of dysfunction, on differentiation levels of adult children of alcoholics. Specifically, it was expected that ACOAs would have lower levels of differentiation and that higher levels of family functioning within alcoholic families would be associated with higher levels of differentiation in ACOAs.

Differentiation of Self

In Bowen family systems theory one of the fundamental tasks of young adults is to become emotionally autonomous from one's family of origin without becoming emotionally cutoff (Bowen 1976, 1978; Carter \& McGoldrick 1989). Key to the development of differentiation is the ability to maintain emotional connectedness while avoiding emotional fusion. Individuals that remain fused with family are locked into their family roles, with few firmly held personal convictions (Bowen 1976, 1978; Carter \& McGoldrick 1989; Skowron \& Friedlander, 1998). These individuals rarely challenge the family belief system and simply remain compliant or rigidly adhere to those beliefs. Emotional cutoff, in contrast, is a pseudoautonomous separation from family marked by reactive emotional distance. Cutoff may be a maladaptive reaction to unresolved fusion with parents (Johnson \& Waldo, 1998; Johnson, Buboltz, \& Seemann, 2003).

According to Bowen $(1976,1978)$, differentiation is associated with an individual's ability to self regulate their emotional reactivity or psychological reactance (Johnson \& Bulboltz, 2000; Skowron \& Friedlander, 1998; Skowron, Holmes \& Sabatelli, 2003; Skowron \& Dendy, 
2004). Individuals with high levels of differentiation have an increased capacity to separate their emotions from intellectual thought (Bowen, 1978). The separation represents the ability to set aside strong emotional content and intentionally shift to rational thought processes when necessary (Skowron \& Friedlander, 1998; Skowron, et al., 2003; Skowron \& Dendy 2004). Conversely, individuals with low levels of differentiation are more emotionally reactive, having a limited capacity to think critically and regulate their emotions during times of stress. Individuals with higher levels of differentiation utilize I positions, i.e., the ability to maintain a strong sense of self and to hold on to personal beliefs when challenged. Low levels of emotional reactivity and the ability to take I positions are associated with more proficient self-regulation (Skowron et al., 2003; Skowron \& Dendy 2004).

Bowen (1978) theorized that differentiation is important for psychological well-being. Research supports this assumption in that higher levels of differentiation are predictive of psychological and psychosocial well-being and moderate the effects of stress on individuals (Kerr \& Bowen 1988; Bohlander, 1999; Jenkins, Buboltz, Schwartz, \& Johnson, 2005; Skowron \& Friedlander 1998, Skowron et al., 2003). Emotional reactivity and emotional cutoff, characteristics of lower levels of differentiation, are predictors of global maladjustment (Skowron \& Friedlander 1998). Marriages with high levels of emotional cutoff are associated with declining levels satisfaction and increased distress (Skowron, 2000; Skowron \& Friedlander 1998). Conversely, low levels of emotional cutoff and reactivity, as well as the ability to take I positions are associated with greater marital satisfaction. Skowron and Platt (2005) found that these characteristics of differentiation combined with problem solving skills predicted lower risks of an adult perpetrating physical child abuse. These same characteristics support secure adult attachments and predict self-regulation or effortful control (Skowron et al., 2003). As may 
PARENTAL ALCOHOLISM 8

be expected, avoidant and anxious attachment styles are associated with high levels of emotional cutoff and emotional reactivity, respectively (Skowron \& Dendy, 2004).

\section{Method}

\section{Procedures and Participants}

Participants were 813 college student volunteers who completed standardized measures, demographic questions, and single-item questions related to experiences in their families of origin, including parental alcoholism status, parental marital status, parental availability and predictability, child abuse, spousal violence, frequency of parental drinking, and length of time living with an alcoholic parent. Child abuse and spousal violence were each assessed, respectively, by asking participants if they had experienced verbal, physical or sexual abuse in their families and if they witnessed verbal or physical violence occurring between their parents. For each of these two items participants were asked to check one answer only (e.g., no abuse or verbal abuse or physical abuse or sexual abuse). Thus, these two questions did not reflect those who experienced or witnessed multiple forms of abuse or violence. Parental alcoholism status was assessed by asking participants if, while they were growing up, one or more of their parents had a drinking problem. Although this item is based upon young adults' memory of their parents' drinking, a single question has been shown by Berkowitz and Perkins (1988) to be a valid method for identifying ACOAs and has been used by previous researchers (e.g., Cavell et al., 1993; Fisher et al., 1993) in place of the Children of Alcoholics Screening Test (Jones, 1982).

The participants included 563 women (69\%), 222 men (27\%), and 28 (4\%) participants who did not identify their gender. Of the participants, 795 provided information on age $(M=$ 21.26 years, $S D=5.91)$. In terms of ethnicity, 805 participants provided information, with 727 (89\%) identifying themselves as Caucasian/Anglo Americans, 29 (4\%) identifying themselves as 
Native Americans, 14 (2\%) identifying themselves as Asian Americans, 11 (1\%) identifying themselves as Hispanic/Latino Americans, 7 (1\%) identifying themselves as African Americans, and $17(2 \%)$ identifying themselves as "other."

Of the 813 participants, $173(21 \%)$ reported that one or more of their parents had a drinking problem. Of the 173 participants in the ACOA group, 121 (70\%) were female, 48 $(28 \%)$ were male, and $4(2 \%)$ did not indicate their gender. In terms of ethnicity, $2(1 \%)$ identified themselves as African American, 3 (2\%) identified themselves as Asian American, 151 (87\%) identified themselves as Anglo/Caucasian American, 4 (2\%) identified themselves as Hispanic/Latino American, 11 (6\%) identified themselves as Native American, and 2 (2\%) identified themselves as "other." The mean age of the participants was 22.15 years old $\underline{\mathrm{SD}}=$ 5.27). Of the ACOA group, 71 (42\%) grew up in intact families and 97 (58\%) grew up in divorced families.

\section{Instruments}

The Self-Report Family Inventory Version II (SFI). The SFI (Beavers \& Hampson, 1990) is comprised of 36 items, which are rated on a 5-point scale, that assess individuals' perceptions of family competence and style. Factor analyses revealed five factors, which measure consistent themes of family life across different samples, from which the subscales for the SFI were developed. The first subscale, Health/Competence, is a global measure of family functioning that assesses themes of happiness, optimism, problem solving and negotiation skills, family love, strength of adult coalitions, autonomy/individuality emphasis, and blaming/responsibility patterns. The second subscale, Conflict, assesses the level of overt unresolved conflict, fighting, blaming, and arguing. The third subscale, Cohesion, assesses the level of satisfaction and happiness attained through togetherness and emphasis on family closeness. The fourth subscale, 
Leadership, assesses the level of strong and consistent patterns of adult leadership in the family. The fifth subscale, Emotional Expressiveness, assesses feelings of closeness, physical and verbal expressions of positive feelings, and the ease with which family members express warmth and caring. Lower scores on the SFI indicate higher levels of family functioning (i.e., more health/competence, more cohesion, less conflict, more expressiveness, and more leadership).

Beavers and Hampson (1990) provided psychometric information about the SFI. The average of the test-retest coefficients across several time periods (one, two, and three months) for each scale were as follows: Health/Competence $(\underline{\mathrm{r}}=.85)$, Conflict $(\underline{\mathrm{r}}=.54)$, Cohesion $(\underline{\mathrm{r}}=.60)$, Leadership $(\underline{r}=.44)$, and Expressiveness $(\underline{r}=.81)$. Construct validity was generally found to be sufficient for the SFI subscales through moderate correlations with other conceptually similar measures (i.e., Locke-Wallace Marital Satisfaction Scale, FACES II, FACES III, and Family Environment Scale).

Differentiation of Self Inventory (DSI). The DSI (Skowron \& Friedlander, 1998) is comprised of 43 items, which are rated on a 6-point scale, that generate four subscale scores. Factor analyses demonstrated support for the four subscales as being "empirically distinct dimensions of a single construct, differentiation of self' (Skowron \& Friedlander, 1998, p. 241). The first subscale, Emotional Reactivity, reflects the degree to which a person responds to environmental stimuli with emotional flooding, emotional lability, or hypersensitivity. The second subscale, I Position, reflects a clearly defined sense of self and the ability to thoughtfully adhere to one's convictions when pressured to do otherwise. The third subscale, Emotional Cutoff, reflects feeling threatened by intimacy and feeling excessive vulnerability in relations with others; this vulnerability leads to fears of engulfment and defensive behaviors such as distancing and denial. The fourth subscale, Fusion with Others, reflects emotional 
overinvolvement with others, including triangulation and overidentification with parents. Higher scores on the DSI reflect higher levels of differentiation (i.e., less fusion, less reactivity, less cutoff, and more I position).

Skowron and Friedlander (1998) provided information about the psychometric properties of the DSI based on three separate studies. Initial construct validity of the DSI was supported as the DSI correlated highly and in the expected direction with a measure of chronic anxiety and with amount and intensity of symptomatic distress. Across several studies, internal consistency coefficients, using Cronbach's alpha, supported moderate to high reliabilities for each of the four subscales (i.e., Emotional Reactivity $=.88$, Emotional Cutoff $=.79$, Fusion with Others $=.70$, and I Position $=.85)$.

\section{Results}

For the present study, internal consistencies were calculated for the DSI and the SFI. The resulting reliability coefficients were .83 for the total DSI scale, .81 for the Emotional Reactivity subscale, .78 for the I Position subscale, .84 for the Emotional Cutoff subscale, and .68 for the Fusion subscale. For the SFI, the coefficients were .93 for the Health/Competence subscale, .88 for the Conflict subscale, .80 for the Cohesion subscale, .50 for the Leadership subscale, and .86 for the Expressiveness subscale. Due to the low levels of internal consistency and stability of the Leadership scale, it was removed from further analyses in the study.

To assess the effects of parental alcoholism on the differentiation levels of adults, MANOVA and univariate follow-ups were calculated. A multivariate $\underline{F}$ ratio was generated from Wilks' Lambda statistic; significant differences between those from alcoholic families and those from nonalcoholic families across the four DSI subscales were found, $\underline{F}(4,749)=6.61, p$ 
$<.001$. See Table 1 for the univariate analyses of variance, means, and standard deviations for each DSI subscale as a function of parental alcoholism status.

To assess the effects of family functioning (i.e., family health/competence) within alcoholic families on differentiation levels of adults, multiple regression analyses were used for each DSI subscale. Family health/competence significantly predicted three of four DSI subscales such that higher levels of family health predicted lower levels of emotional cutoff, $\underline{F}$ $(1,166)=10.25, \underline{p}<.01$, higher levels of I position, $\underline{\mathrm{F}}(1,170)=3.57, \underline{\mathrm{p}}<.05$, and higher levels of fusion, $\underline{F}(1,169)=25.22, \underline{p}<.001$.

To assess the unique effects of each family relationship factor that contributes to overall family health (i.e., conflict, cohesion, and emotional expressiveness) on differentiation levels of adults from alcoholic families, multiple regression analyses were used for each DSI subscale. Conflict significantly predicted two DSI subscales such that higher levels of conflict predicted lower levels of I position, $\underline{\mathrm{F}}(1,170)=12.09, \underline{\mathrm{p}}<.001$ and higher levels of emotional cutoff, $\underline{\mathrm{F}}$ $(1,166)=9.57, \underline{p}<.01$. Cohesion was significant on one DSI subscale such that higher levels of cohesion predicted lower levels of I position, $\underline{\mathrm{F}}(1,170)=5.01, \underline{\mathrm{p}}<.05)$. Emotional expressiveness was significant on one DSI subscale such that higher levels of expressiveness predicted higher levels of fusion, $\underline{\mathrm{F}}(1,169)=5.94, \mathrm{p}<.05$.

To assess the effects of parental marital status on differentiation levels of ACOAs, MANOVA was used to compare ACOAs from intact and from divorced families on dimensions of differentiation. Analyses of variance revealed a significant effect on one of the DSI subscales such that ACOAs from divorced families exhibited higher levels of I position than did those from intact families, $\underline{\mathrm{F}}(1,166)=6.49, \mathrm{p}<.05$. 
To assess the effects of child abuse on differentiation levels of ACOAs, MANOVA was used to compare various forms of child abuse on dimensions of differentiation. Analyses of variance revealed significant effects of child abuse on two of the DSI subscales. Post hoc analyses revealed that the significant differences were between "no abuse" and verbal abuse, with verbal abuse predicting less fusion, $\underline{F}(3,167)=6.37, \mathrm{p}<.001$, and more emotional cutoff, $\underline{F}(3,167)=2.73, p<.05$.

To assess the effects of spousal violence on differentiation levels of ACOAs, MANOVA was used to compare various forms of spousal violence on dimensions of differentiation. Analyses of variance revealed significant effects of spousal violence on one DSI subscale, namely I position. Post hoc analyses revealed that the significant differences were between "no spousal violence" and witnessing physical spousal abuse, with witnessing physical spousal abuse predicting lower levels of I position, $\underline{\mathrm{F}}(2,166)=5.11, \mathrm{p}<.01$.

To assess the unique effects of other experiences on differentiation of ACOAs, simultaneous multiple regression analyses were employed. Over and above the other predictor variables, the availability of the parent that the ACOA identified as being the most problematic drinker was significant on one DSI subscale such that greater availability predicted higher levels of fusion, $\underline{F}(1,155)=3.99, \mathrm{p}<.05$. The availability of the parent not identified as being the most problematic drinker was significant on two of the DSI subscales such that greater availability predicted higher levels of fusion, $\underline{F}(1,155)=7.88, \mathrm{p}<.01$, and lower levels of emotional cutoff, $\underline{\mathrm{F}}(1,153)=7.58, \mathrm{p}<.01$. The length of time that ACOAs lived in the same household with the parent that they identified as having the most problematic drinking was significant on one DSI subscale such that the longer that ACOAs lived with the most problematic drinker the higher the level of reactivity, $\underline{F}(1,156)=3.50, p<.05$. Lastly, the frequency of 
PARENTAL ALCOHOLISM 14

drinking by the most problematic drinker and the behavioral predictability of the parent that the ACOA identified as being the most problematic drinker did not significantly predict any of the DSI subscales.

\section{Discussion}

Results suggest that parental alcoholism effects differentiation levels across all four DSI subscales, providing support for Maynard's (1997) findings. Specifically, ACOAs seem to be more emotionally reactive and have lower levels of I position than non-ACOAs, indicating a tendency to respond to environmental stimuli with emotional flooding, emotional lability, or hypersensitivity and a lack of clearly defined sense of self. ACOAs also seem to be more emotionally cutoff and experience lower levels fusion than non-ACOAs. Although lower levels of fusion are often associated with higher levels of differentiation, the high levels of emotional cutoff combined with low levels of fusion seem to reflect a disconnected interpersonal style. This conclusion is supported by the lack of satisfaction ACOAs have with their marriage and with their children (Kerr \& Hill, 1992b). More support for this assertion is found in findings that suggest that ACOAs, as part of a larger population of adult children of dysfunctional families, are more likely to experience avoidant or anxious attachment marked by a compromised ability to develop trust and intimacy (Hadley, Holloway, \& Mallinckrodt, 1993).

Results suggest that certain experiences within alcoholic families influence the development of differentiation in ACOAs. Overall family health seems to bolster levels of differentiation of ACOAs with a decrease in emotional cutoff and an increase in I position. Family conflict had an adverse effect on levels of differentiation levels of ACOAs, predicting decreased levels of I position and increased levels of emotional cutoff. However, overall family health, emotional expressiveness, and family cohesion seem to also predict higher levels of 
fusion. These unexpected results may point to a tendency of alcoholic families who are relationally involved to become over-involved. It may also point to the difficulty of defining healthy limits for family concepts such as cohesion and fusion (e.g., When does cohesion become problematic over-involvement?); this will be discussed in the Limitations and Suggestions for Future Research section.

In addition, specific indices of family health and dysfunction such as parental availability, parental divorce, experiencing child abuse, and witnessing spousal violence seem to have varying affects on differentiation levels of ACOAs. Results indicate that when the non-drinking parent was consistently available, ACOAs are less likely to experience emotional cutoff. When the non-drinking or the problem-drinking parent are more available, ACOAs are more likely to experience higher levels of fusion. As was previously mentioned, the nature of fusion in these circumstances has not been clearly defined and may represent co-dependent relationships or. parentification of the child. Results also suggest that ACOAs who were verbally abused as children are more likely to be less fused and more emotionally cutoff from their families of origin, indicating that verbal abuse within alcoholic families increases emotional distance. Children witnessing spousal physical violence tends to lead to lower levels of I position; in other words, ACOAs who witnessed physical violence between their parents seem to have a less defined sense of self and less ability to adhere to their own convictions.

Results also indicate that the longer that ACOAs live with problem-drinking parents the higher the level of emotional reactivity. Lastly, results suggest that ACOAs whose parents divorced are more likely to have higher levels of I position, a marker of higher levels of differentiation. This finding contradicts earlier research on differentiation of self in which adult children from divorced families were found to have lower levels of differentiation than adults 
from intact families (Johnson, Thorngren, \& Smith, 2001). A possible conclusion is that parental divorce provides children with less time and exposure to the problem-drinking parent, which moderates the detrimental effects of growing up in an alcoholic family.

\section{Limitations and Suggestions for Future Research}

A possible limitation in this study is the operationalization of the theoretical constructs, which may prove helpful for future researchers. In partuclar, the construct of fusion merits further examination. Higher levels of interpersonal fusion are theoretically associated with lower levels of differentiation. However, in this study ACOAs were less fused than non-ACOAs. Overall family health, cohesion, and emotional expressiveness predicted fusion among ACOAs. Also, higher levels of parental availability (either parent) for ACOAs also predicted higher levels of fusion. The DSI does not define a cutoff score that indicates when levels of fusion reach clinical significance. It may be that low levels of fusion indicate low levels of interpersonal involvement among family members rather than low levels of over-involvement. This interpretation is supported by the findings in this study that suggest that low levels of fusion occur when there are high levels of emotional cutoff. A more precise definition of when family involvement becomes over-involvement is needed to determine healthy and maladaptive levels of connection. One step towards remedying this issue is the development of a new Fusion with

Others subscale for the DSI by Skowron \& Schmitt (2003); the current study used the old fusion subscale.

Contrary to earlier findings that children of divorced families generally had lower levels of differentiation (Johnson, Thorngren, \& Smith, 2001), ACOAs whose parents divorced were more likely to express an I position. As was previously mentioned, it may be that a decrease in conflict and exposure to the problem drinking parent may help moderate the effects ACOAs 
often experience. However, a more thorough understanding of the effects of divorce on alcoholic families is needed before a clear relationship can be established between family of origin divorce and level of differentiation in ACOAs. Further research avenues on the impact of divorce on ACOAs' differentiation also includes: determining if there is a relationship between custody type and differentiation levels and making a more specific comparison of the dimensions of family functioning in both divorced and intact alcoholic families.

Another limitation of this study is that single-item questions were used to assess for parental alcoholism, parental divorce, child abuse, spousal violence, and grandparent alcoholism. In general, single-item questions are weaker psychometrically than multi-item questions and should be interpreted with caution. More specifically, a single-item question for parental alcoholism forces respondents into an all-or-nothing choice. This dichotomized choice does not reflect the continuum of severity or the context of the drinking. Newcomb and Richards (1995) indicate that dichotomizing parental alcoholism status minimizes variations in the extent of the exposure, the variability of the use and impairment, and other subtleties of experience of individuals who are raised with a parent with alcohol problems. In other words, not all alcoholics or families with alcoholics are the same. Recent research highlights this issue by describing different types of alcoholics with recommended treatments for each type (Moss, Chen, \& Yi, 2007).

Similarly, several researchers have indicated that alcoholic families can not easily be discriminated from dysfunctional families or families experiencing other kinds of stressors (Alford, 1998, Fischer et al., 2000; Wright \& Heppner, 1993). Mothersead, Kivlighan, and Wynkoop (1998) argue that the validity of classifying ACOAs as a separate group is under question. A study by Scharff et al. (2004) found main effects of family dysfunction and parental 
alcoholism status as well as interaction effects of ACOA and family roles; they contend that family dysfunction and ACOA status are both important factors to explore and that researchers can fail to recognize the impact of parental alcoholism due to the interaction with family roles. The present study attempted to assess for contextual family information within alcoholic families, but questions remain. Clearly, these issues have continued conceptual and practical significance and warrant further research and discussion.

\section{Implications for Clinicians}

Despite limitations, the results of this study have implications for clinicians. ACOAs seem to develop lower levels of differentiation than do non-ACOAs, which is clinically significant as low levels of differentiation have been associated with a variety of adult psychological difficulties. In working with ACOAs, counselors should be aware that their clients are more likely than non-ACOAs to have higher levels of emotional reactivity and/or emotional cutoffs in their relationships. ACOAs are less likely to have developed I positions or learned to make non-reactive decisions in their lives. Counselors can help clients learn to balance emotional and rational information to make thoughtful rather than reactive decisions especially related to major life decisions such as career and educational, lifestyle, and intimate relationship choices. Whether the counselor is working with a family or a specific young adult, the counselor should promote the formation of separate but healthy relationships between children and parents.

Substance abuse counselors, particularly those working with families affected by alcohol use/abuse disorders, may want to consider those aspects of family function that impact differentiation levels in family members. Suggested work within the family includes determining interpersonal patterns of dysfunctional closeness and distance as well as specific 
family patterns and boundaries. Suggested goals include strengthening the overall health of the family, decreasing overt conflict, and supporting the development of functional family cohesion. To achieve this higher level of family health, counselors can teach family members more effective conflict resolution skills, to recognize and replace dysfunction family boundaries, and promoting interactions in new family subsystems. Because differentiation is a result of multigenerational process, exploring family of origin experiences through the use of genograms may provide important insights. Counselors can help individuals and families explore the patterns and roles that they would like to carry on as well as those patterns and roles that they hope to change. 


\section{References}

Alford, K. (1998). Family roles, alcoholism, and family dysfunction. Journal of Mental Health Counseling, 20, 250-260.

Anda, R. F., Whitfield, C. L., Felitti, V. J., Chapman, D., Edwards, V. J., Dube, S. R., \& Williamson, D. F. (2002). Adverse childhood experiences, alcoholic parents, and later risks of alcoholism and depression. Psychiatric Services, 53(8), 1001-1009. doi:10.1176/appi.ps.53.8.1001

Beavers, W. R., \& Hampson, R. B. (1990). Successful families. New York: Norton.

Beesley, D., \& Stoltenberg, C. D. (2002). Control, attachment style, and relationship satisfaction among adult children of alcoholics. Journal of Mental Health Counseling, 24(4), 281298.

Berkowitz, A., \& Perkins, H. W. (1988). Personality characteristics of children of alcoholics. Journal of Consulting and Clinical Psychology, 56(2), 206-209.

Bohlander, R. W. (1999). Differentiation of self, need fulfillment, and psychological well-being in married men. Psychological Reports, 84, 1274-1280.

Bowen, M. (1976). Theory in the practice of psychotherapy. In P. J. Guerin, Jr. (Ed.), Family therapy: Theory: and practice (pp. 42-90). New York: Garner Press.

Bowen, M. (1978). Family therapy in clinical practice. New York: Jason Aronson.

Campbell, J., Masters, M., \& Johnson, M. (1998). Relationship of parental alcoholism to familyof-origin functioning and current marital satisfaction. Journal of Addictions \& Offender Counseling, 19(1), 7-14.

Carter, B., \& McGoldrick, M. (Eds.). (1989). The changing family life cycle: A framework for family therapy (2nd ed.). Boston: Allyn and Bacon. 
Cavell, T.A., Jones, D.C., Runyun, R.D., Constantin-Page, L.P., \& Velasquez, J.M. (1993). Perceptions of attachment and the adjustment of adolescents with alcoholic fathers. Journal of Family Psychology, 7, 204-212.

Chase, N. D., Deming, M. P., \& Wells, M. C. (1998). Parentification, parental alcoholism, and academic status among young adults. American Journal of Family Therapy, 26(2), 105114.

Chassin, L., Pitts, S., DeLucia, C., \& Todd, M. (1999). A longitudinal study of children of alcoholics: Predicting young adult substance use disorders, anxiety, and depression. Journal of Abnormal Psychology, 108(3), 106-119. doi:10.1037/0021-843X.108.1.106

Cuijpers, P., Langendoen, Y., \& Bijl, R. (1999). Psychiatric disorders in adult children of alcoholics, first onset and comparison with other risk factors. Addiction, 94(10), 14891498. doi:10.1046/j.1360-0443.1999.941014895.x

Deming, M. P., Chase, N. D., \& Karesh, D. (1996). Parental alcoholism and perceived levels of family health among college freshmen. Alcoholism Treatment Quarterly, 14(1), 47-57.

Devine, C., \& Braithwaite, V. (1993). The survival roles of children of alcoholics: Their measurement and validity. Addiction, 88(1), 69-78. doi:10.1111/j.13600443.1993.tb02764.x

Ellis, D. A., Zucker, R. A., \& Fitzgerald, H. E. (1997). The role of family influences in development and risk. Alcohol Health and Research World, 21(3), 218-226.

Fisher, G. L., Jenkins, S. J., Harrison, T. C., \& Jesch, K. (1993). Personality characteristics of adult children of alcoholics, other adults from dysfunctional families and adults from non-dysfunctional families. International Journal of Addictions, 28, 477-485. 
Fischer, K. E., Kittleson, M., Ogletree, R., Welshimer, K., Woehlke, P., \& Benshoff, J. (2000). The relationship of parental alcoholism and family dysfunction to stress among college students. Journal of American College Health, 48(4), 151-156.

Garbarino, C., \& Strange, C. (1993). College adjustment and family environments of students reporting parental alcohol problems. Journal of College Student Development, 34(4), 261-266.

Goglia, L., Jurovic, G., Burt, A., \& Burge-Callaway, K. (1992). Generational boundary distortions by adult children of alcoholics: Child-as-parent and child-as-mate. American Journal of Family Therapy, 20(4), 291-299.

Grant, B. F. (2001). Estimates of US children exposed to alcohol abuse and dependence in the family. American Journal of Public Health, 90(1), 112-115.

Grant, B. F., Dawson, D. A., Stinson, F. S., Chou, P. S., Dufour, M. C., \& Pickering, R. P. (2004). The 12-Month prevalence and trends in DSM-IV alcohol abuse and dependence: United States, 1991-1992 and 2001-2002. Drug and Alcohol Dependence, 74(3), 223234. doi:10.1016/j.drugalcdep.2004.02.004

Haber, J. E. (1993). A construct validity study of a differentiation of self scale. Scholarly Inquiry for Nursing Practice, 7, 165-178.

Hadley, J. A., Holloway, E. L., \& Mallinckrodt, B. (1993). Common aspects of object relations and self-representations in offspring from disparate dysfunctional families. Journal of Counseling Psychology, 3, 348-356. doi:10.1037/0022-0167.40.3.348

Hall, C. W., Bolen, L. M., \& Webster, R. E. (1994). Adjustment issues with adult children of alcoholics. Journal of Clinical Psychology, 50, 786-792. doi:10.1002/10974679(199409)50:5<786::AID-JCLP2270500517>3.0.CO;2-C 
Hall, C. W., \& Webster, R. E. (2002). Traumatic symptomatology characteristics of adult children of alcoholics. Journal of Drug Education, 32(3), 195-211. doi:10.2190/U29WLF3W-748L-A48M

Hardwick, C. J., Hansen, N. D., \& Bairnsfather, L. (1995). Are adult children of alcoholics unique? A study of object relations and reality testing. International Journal of the Addictions, 30(5), 525-539.

Hart, K. E., \& McAleer, M. (1997). Anger coping style in adult children of alcoholics. Addiction Research, 5(6), 473-486.

Harter, S. L. (2000). Psychosocial adjustment of adult children of alcoholics: A review of the recent empirical literature. Clinical Psychology Review, 20(3), 311-337. doi:10.1016/S0272-7358(98)00084-1

Harter, S. L., \& Taylor, T. L. (2000). Parental alcoholism, child abuse, and adult adjustment. Journal of Substance Abuse, 11(1), 31-44. doi:10.1016/S0899-3289(99)00018-8

Harter, S. L., \& Vanecek, R. J. (2000). Cognitive assumptions and long-term distress in survivors of childhood abuse, parental alcoholism, and dysfunctional family environments. Cognitive Therapy \& Research, 24(4), 445-472. doi:10.1023/A:1005531803919

Hawkins, C. A. (1997). Disruption of family rituals as a mediator of the relationship between parental drinking and adult adjustment in offspring. Addictive Behaviors, 22(2), 219-231. doi:10.1016/S0306-4603(96)00011-1

Jenkins, S. M., Buboltz, W. C., Schwartz, J. P., \& Johnson, P. (2005). Differentiation of self and psychosocial development. Contemporary Family Therapy, 27, 251-261. doi:10.1007/s10591-005-4042-6 
Johnson, P. (2001). Dimensions of functioning in alcoholic and nonalcoholic families. Journal of Mental Health Counseling, 23, 127-136.

Johnson, P. (2002). Predictors of family functioning within alcoholic families. Contemporary Family Therapy 2, 371-384. doi:10.1023/A:1015307626704

Johnson, P., \& Buboltz, W. C. (2000). Differentiation of self and psychological reactance. Contemporary Family Therapy, 22, 91-102. doi:10.1023/A:1007774600764

Johnson, P., Buboltz, W. C., \& Seemann, E. (2003). Ego identity status: A step in the differentiation process. Journal of Counseling and Development, 81, 191-195.

Johnson, P., Thorngren, J. M., \& Smith, A. J. (2001). Parental divorce and family functioning: Effects on differentiation levels in young adults. The Family Journal, 9, 265-272. doi:10.1177/1066480701093005

Johnson, P., \& Waldo, M. (1998). Integrating Minuchin's boundary continuum and and Bowen's differentiation scale: A curvilinear representation. Contemporary Family Therapy, 20, 403-413. doi:10.1023/A:1022429332033

Jones, J. (1982). The children of alcoholics screening test. Chicago: IL. Family Recovery Press. Jones, J., \& Kinnick, B. C. (1995). Adult children of alcoholics: Characteristics of students in a university setting. Journal of Alcohol \& Drug Education, 40(2), 58-70.

Kerr, A. S., \& Hill, E. W. (1992a). An exploratory study comparing ACoAs to non-ACoAs on family of origin relationships. Australian Journal of Marriage \& Family, 13(1), 24-33.

Kerr, A. S., \& Hill, E. W. (1992b). An exploratory study comparing ACoAs to non-ACoAs on current family relationships. Alcoholism Treatment Quarterly, 9(1), 23-38. doi:10.1300/J020V09N01_02 
Kerr, M. E., \& Bowen, M. (1988). Family: evaluation: An approach based on Bowen theory. New York: Norton.

Larson, J. H., \& Thayne, T. R. (1998). Marital attitudes and personal readiness for marriage of young adult children of alcoholics. Alcoholism Treatment Quarterly, 16(4), 59-73.

Maynard, S. (1997). Growing up in an alcoholic family system: The effect on anxiety and differentiation of self. Journal of Substance Abuse, 9, 161-170. doi:10.1016/S08993289(97)90014-6

Melchert, T. P. (2000). Clarifying the effects of parental substance abuse, child sexual abuse, and parental caregiving on adult adjustment. Professional Psychology: Research and Practice, 31(1), 64-69.

Moss, H. B., Chen, C.M., \& Yi, H-y. (2007). Subtypes of alcohol dependence in a nationally representative sample. Drug and Alcohol Dependence, 91, 149-158.

Mothersead, P.K., Kivlighan, D.M., \& Wynkoop, T.F. (1998). Attachment, family dysfunction, parental alcoholism, and interpersonal distress in late adolescence: A structural model. Journal of Counseling Psychology, 45, 196-203.

Newcomb, M.D., \& Richards, S. (1995). Parent drug-use problems and adult intimate relations: Associations among community samples of young adult women and men. Journal of Counseling Psychology, 42, 141-154.

Scharff, J.L., Broida, J.P., Conway, K., \& Yue, A. (2004). The interaction of parental alcoholism, adaptation role, and familial dysfunction. Addictive Behaviors, 29, 575-581.

Senchak, M., Leonard, K. E., Greene, B. W., \& Carroll, A. (1995) Comparisons of adult children of alcoholic, divorced, and control parents in four outcome domains. Psychology of Addictive Behaviors, 9(3), 147-156. doi:10.1037/0893-164X.9.3.147 
Shapiro, D. H., Weatherford, V., Kaufman, E., \& Broenen, R. E. (1994). A control profile of adult children of alcoholics: A preliminary investigation. American Journal of Drug and Alcohol Abuse, 20(2), 247-262

Sher, K. J. (1997). Psychological characteristics of children of alcoholics. Alcohol Health \& Research World, 21(3), 247-254.

Sher, K. J., Walitzer, K., Wood, P., \& Brent, E. (1991). Characteristics of alcoholics: Putative risk factors, substance use and abuse, and psychopathology. Journal of Abnormal Psychology, 100(4), 427-448. doi:10.1037/0021-843X.100.4.427

Sheridan, M. J., \& Green, R. G. (1993). Family dynamics and individual characteristics of adult children of alcoholics: An empirical analysis. Journal of Social Service Research, 17(12), 73-97. doi:10.1300/J079v17n01_04

Skowron, E. A. (2000). The role of differentiation of self in marital adjustment. Journal of Counseling Psychology, 47, 229-237. doi:10.1037/0022-0167.47.2.229

Skowron, E. A., \& Dendy, A. K. (2004). Differentiation of self and attachment in adulthood: Relational correlates of effortful control. Contemporary Family Therapy, 26(3), 337-357. doi:10.1023/B:COFT.0000037919.63750.9d

Skowron, E. A., \& Friedlander, M. L. (1998). The Differentiation of Self Inventory: Development and initial validation. Journal of Counseling Psychology, 45, 1-11. doi:10.1037/0022-0167.45.3.235

Skowron, E. A., Holmes, S. E., \& Sabatelli, R. M. (2003). Deconstructing differentiation: Selfregulation, interdependent relating, and well being in adulthood. Contemporary Family Therapy, 25, 111-129. doi:10.1023/A:1022514306491 
Skowron, E. A., \& Platt, L. F. (2005). Differentiation of self and child abuse potential in young adulthood. Family Journal, 13(3), 281-290. doi:10.1177/1066480705276314

Skowron, E. A., \& Schmitt, T. A. (2003). Assessing interpersonal fusion: Reliability and validity of a new DSI Fusion with others subscale. Journal of Marital and Family Therapy, 29, 209-222. doi:10.1111/j.1752-0606.2003.tb01201.x

Wright, D., \& Heppner, P.P. (1993). Examining the well-being of non-clinical college students: Is knowledge of the presence of parental alcoholism useful? Journal of Counseling Psychology, 40, 324-334. 
Table 1

$\underline{\text { Univariate Analyses, }}$, Means, and Standard Deviations for each DSI Subscale as a Function of

$\underline{\text { Parental Alcoholism Status }}$

\begin{tabular}{|c|c|c|c|c|c|}
\hline \multirow[b]{2}{*}{ Variable } & \multirow{2}{*}{$\begin{array}{l}\text { Univariate Analyses } \\
\qquad \underline{F}\end{array}$} & \multicolumn{2}{|c|}{ Non ACOA } & \multicolumn{2}{|c|}{$\mathrm{ACOA}$} \\
\hline & & $\underline{\mathrm{M}}$ & $\underline{\mathrm{SD}}$ & $\underline{\mathrm{M}}$ & $\underline{\mathrm{SD}}$ \\
\hline Emotional Cutoff & $11.21 * *$ & 55.50 & 10.41 & 52.45 & 10.46 \\
\hline Fusion & $9.62 * *$ & 23.12 & 6.92 & 25.02 & 7.63 \\
\hline Emotional Reactivity & $5.43 *$ & 37.34 & 9.37 & 35.43 & 9.93 \\
\hline I Position & $7.96 * *$ & 46.11 & 8.60 & 44.00 & 8.91 \\
\hline
\end{tabular}

$\underline{\text { Note. }}$ Higher scores indicate more differentiation (i.e., less emotional cut off, less fusion, less emotional reactivity, and more I position).

${ }^{*} \underline{p}<.05 .{ }^{* *} \underline{p}<.01$. 